or as Prof. Giorgi writes it

$$
K_{0}=\frac{1}{4 \pi} \times 10^{2} L,
$$

where $L$ stands for the unit of length, the metre.

In the above, for the sake of simplicity, Coulomb's laws have been assumed as the basis of the theory on which the system rests. This, however, is by no means necessary. In a very interesting article in the "Enciclopedia ItalianaElettricita, Theoria della", to which Prof. Giorgi very kindly referred the present writer in reply to a request for information on some points of theory, he has in the most lucid manner "developed the three fundamental schemes, preMaxwellian, Maxwellian and electronic". Any of these can be taken as the starting point.

As Prof. Giorgi stated in a paper read before the Electrical Congress at St. Louis in 1904, neither the C.G.S. electrostatic nor the C.G.S. electromagnetic system is touched. Scientific workers will be free to use any one of these systems without modification, or substitute for them his absolute practical system.

To sum up, quoting again from the same paper :

"In order to derive electric and magnetic units from mechanical units, a fourth fundamental unit is necessary. In the C.G.S. electrostatic and the C.G.S. electromagnetic systems, the fourth unit assumed is respectively the electrostatic or the electromagnetic constant of free ether, but this has many disadvantages. For the absolute practical system the fourth unit is the ohm." It would be more accurate to say the "international ohm, defined as the resistance of a certain column of mercury".

It should be noted, of course, that the two changes from the C.G.S. system suggested by Prof. Giorgi are quite independent.

Heaviside's suggestion as to the $4 \pi$ could be introduced without adopting Prof. Giorgi's proposal to take the international ohm as the fourth independent unit.

R. T. G.

${ }^{1}$ NATURE, 180, 368, Sept. 3, 1932.

\title{
The Inheritance of Acquired Habits
}

By Prof. E. W. MacBride, F.r.s.

$\mathrm{F}^{\mathrm{o}}$ OR the last five years, experiments to test the heritability of acquired habit have been in progress in the Zoological Laboratory of the Imperial College of Science under my supervision ; and an account of the work may be of interest to readers of NATURE.

The first part of the results of these experiments has been published by the Royal Society: the second part is almost ready for publication. Miss Sladden, who carried out the work, began by rearing the young of Salamandra maculosa and the eggs of Alytes obstetricans, thus endeavouring to repeat Kammerer's work. It became evident, however, that we did not possess the equipment necessary to provide the conditions which would induce these animals to breed. We succeeded in confirming some of Kammerer's statements about the effect of the environment on the habits of one generation. Thus it is quite possible to induce Alytes, normally a land animal, to adopt an aquatic life ; and in regard to Salamandra we were enabled to explain Herbst's failure to obtain Kammerer's results.

There are two distinct races of Salamandra maculosa, an eastern and a western. In the latter, which inhabits the Jura and the Vosges, the yellow pigment is arranged in two longitudinal bands on the back, over a general body colour of black. Miss Sladden has reared animals of this race from birth to an age of three years in boxes painted inside with bright yellow and also in boxes painted deep black inside. In neither case could we detect any alteration in the amount of yellow pigment as a result of the colour of the background. In the eastern race, however, which formed the subject of Kammerer's researches, the yellow pigment is arranged as a series of spots over a black background; and by experiments conducted by Mr. E. Boulenger, then curator of reptiles in the Zoological Gardens, and by myself, during the years 1919-1924, we were able to show that animals of this race exposed for long periods to a black environment do show definite reduction of the yellow pigment. But even if Miss Sladden had been successful in getting her animals to breed, the length of time involved would have been prohibitive, since the adult condition is only attained after four years' growth. Therefore we sought for a convenient experimental animal in which the generations succeeded each other more rapidly.

Some years ago (1912-1915), in conjunction with another pupil (Miss Jackson, afterwards Mrs. Meinertzhagen), I conducted experiments on breeding the stick-insect, Carausius morosus, and I found that this insect, whose normal food in England is privet, could be forced by starvation to feed upon ivy. I therefore suggested to Miss Sladden that she should test the development of this ivy-feeding habit. This insect offers great advantages when used as an experimental animal. It is parthenogenetic: males only appear in small numbers every five or six generations and when they do appear they are at once recognisable by their smaller size and different coloration. The parthenogenetic insect produces about 150 eggs a year which take about three months to develop: there is no metamorphosis and as there are no wings the nymph is morphologically similar to the adult.

The plan adopted was to isolate the just hatched young, keeping each one in a separate box. These boxes were made of metal: they were circular and had glass covers. In each box was placed a small piece of ivy leaf. At the end of two days 
about ten per cent of the insects had begun to eat ivy, the rest had not touched it. If we had reared from these insects alone we should have been accused of selection: but we adopted a different plan (suggested by my colleague, Mr. Hewer). The ninety per cent which refused ivy were given a bit of privet leaf to eat and so rescued from starvation. Then after one day the privet was removed and the insect was again provided with ivy. This second provision of ivy was called the 'second presentation'. If after two days more the insect still refused ivy, it was again given privet for a day. The majority of the insects accepted ivy at the second presentation, but some held out until the third, fourth, or even fifth, presentation, and one recalcitrant held out until the tenth presentation.

We started the experiments with 125 females. All the young which accepted ivy at the same presentation, to whatever mother they belonged, were classed together, and when they in turn became adult the eggs of each class were mixed together. From each mixture 100 eggs were selected in order to rear the next generation. In the second generation, in place of ten per cent no less than eighty per cent of the insects accepted ivy when first presented, that is, at the first presentation : in all, 800 insects were tested. In the third generation ninety-five per cent accepted ivy at the first opportunity and 2,000 insects were tested.

Thus with these insects, we reached exactly the same conclusions as those arrived at by Prof. McDougall with regard to induced habits in rats, namely, that when members of one generation are compelled to adopt a new habit, a residual effect of this habit is carried over to the next generation, so that the young insects adopt the new habit more quickly than did their parents. We claim, however, that the stick-insect gives more conclusive results than the rat, because although we think that Prof. McDougall has overcome all his difficulties, yet there were very serious objections to be faced with rats, such as possible masssuggestion, parental training, etc., which are obviously inapplicable to insects.

What many people fail to realise, however, is that this transference of a residual effect of habit is the central principle of Lamarckism, clearly and unequivocally expressed by Lamarck himself. He said that "the environment produces no direct effect on the animal", but by making new needs (for example, the neeessity of eating ivy or starving) it forces the animal to make new efforts to satisfy them, and "if these needs continue for a long time then the animal's efforts become habits" and habits by causing the use of some organs more and others less bring about the enlargement of the former and the diminution in size of the latter; and these changes are preserved by reproduction.

This article is written in the hope that other investigators will take up this question and repeat the experiments using other animals, especially other insects, as subjects; for only by such experiments can this fundamental principle be settled. Indeed, experiments with the larvæ of moths were begun some years ago by Dr. Thorpe, of Cambridge. The attractive feature about such experiments is that the percentage of mortality is very low, so that the agency of 'chance' or 'natural selection' is excluded. Prof. Woltereck, whose great book "Grundzüge einer allgemeinen Biologie" was reviewed in NATURE of December 17, 1932, removed Cladoceran Crustacea from northern lakes to Lake Nemi in Italy. When he examined the transported stock after twenty years he found them much altered in shape : when he again re-transferred some of this stock to the post-glacial lakes of their ancestry they reverted to their original shape-but only gradually during the course of several generations.

The Linnean Society recently had the privilege of hearing Prof. Woltereck deliver an address on the fauna of recent lakes in many lands. Summing up the evidence, Prof. Woltereck concludes that the time since the recession of the ice of the last phase of the glacial age, that is, about 10,000 years, has only sufficed for the production of now races : for the production of new species we must go back to pre-glacial times possibly 500,000 years ago. As I remarked in my comments on the lecture it would be hard lines on the experimenter if he had to live and experiment for 10,000 years, before he could hope to produce a new heritable structure, but heritable changes of habit in small rapidly breeding animals may be observed after experiments lasting from five to ten years.

Students of mutation, that is, 'geneticists', will naturally inquire what is the relation between these changes of habit and mutations. That is a question for future study; here only certain tentative suggestions can be offered. From the study of the few cases in which mutations have been experimentally produced by such agencies as X-rays and heat, it may be concluded that they are due to some damage to the developmental machinery of the nucleus in the germ cells. They, and not the Lamarckian changes, are the results of the "direct action of the environment". So long as malign conditions surrounding early development persist, the mutations are faithfully inherited, but if the organism can be replaced in its natural environment, then in a limited number of generations they pass off and the original constitution reasserts itself. In 1790 Capt. Cook introduced the English domestic pig into New Zealand in order to induce the Maoris to abstain from cannibalism. The animals escaped into the woods, and by 1840 had increased to herds of at least 40,000 in number and had assumed all the characters of the ancestral wild boar, including the fierce tusks - although in New Zealand there were no enemies which required such weapons to drive them off. Mutations seemingly are more surface phenomena than racial habits: they are indeed what Johanssen the inventor of the word 'gene' called them, "superficial disturbances of the chromosomes", but racial habits belong to the inmost core of the heritable constitution. 